EUROPHYSICS AND WORLD PHYSICS JOURNALS IN COMPARISON

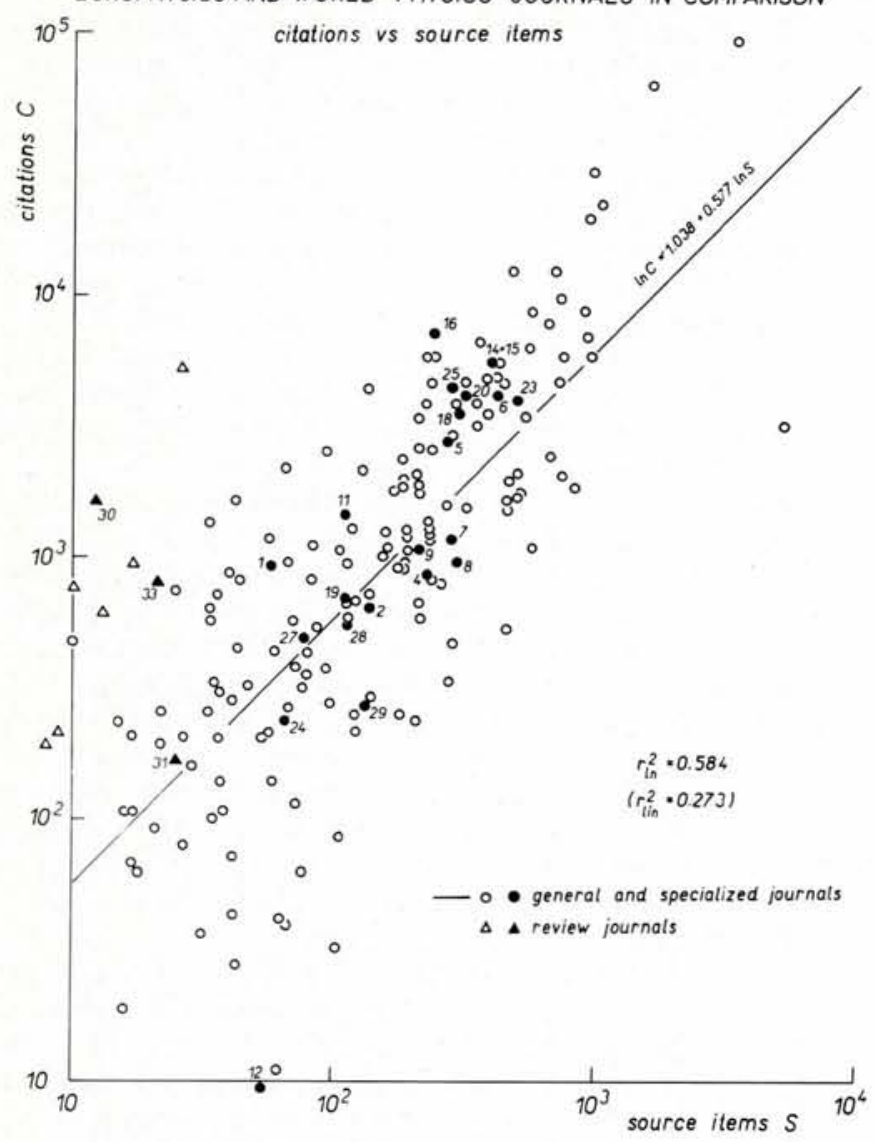

EUROPHYSICS AND WORLD PHYSICS JOURNALS IN COMPARISON

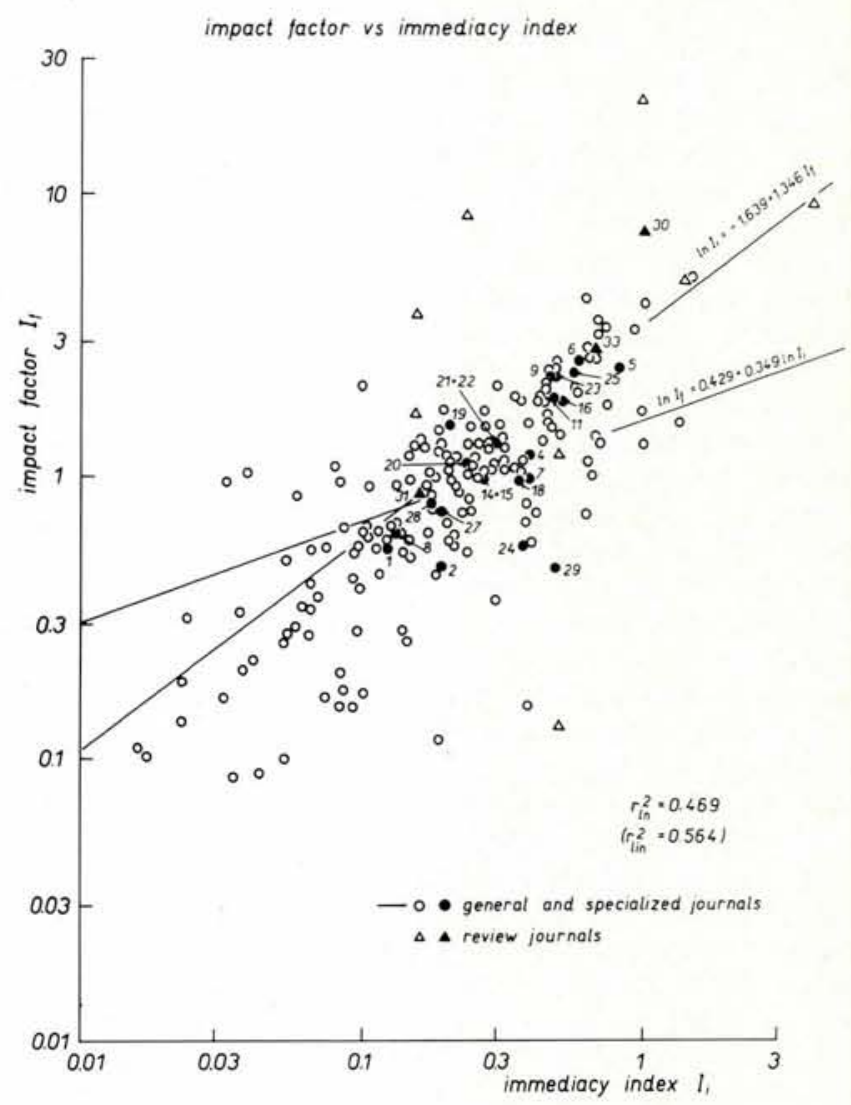

\title{
Citation Patterns in Physics Journals
}

EUROPHYSICS AND WORLD PHYSICS JOURNALS IN COMPARISON

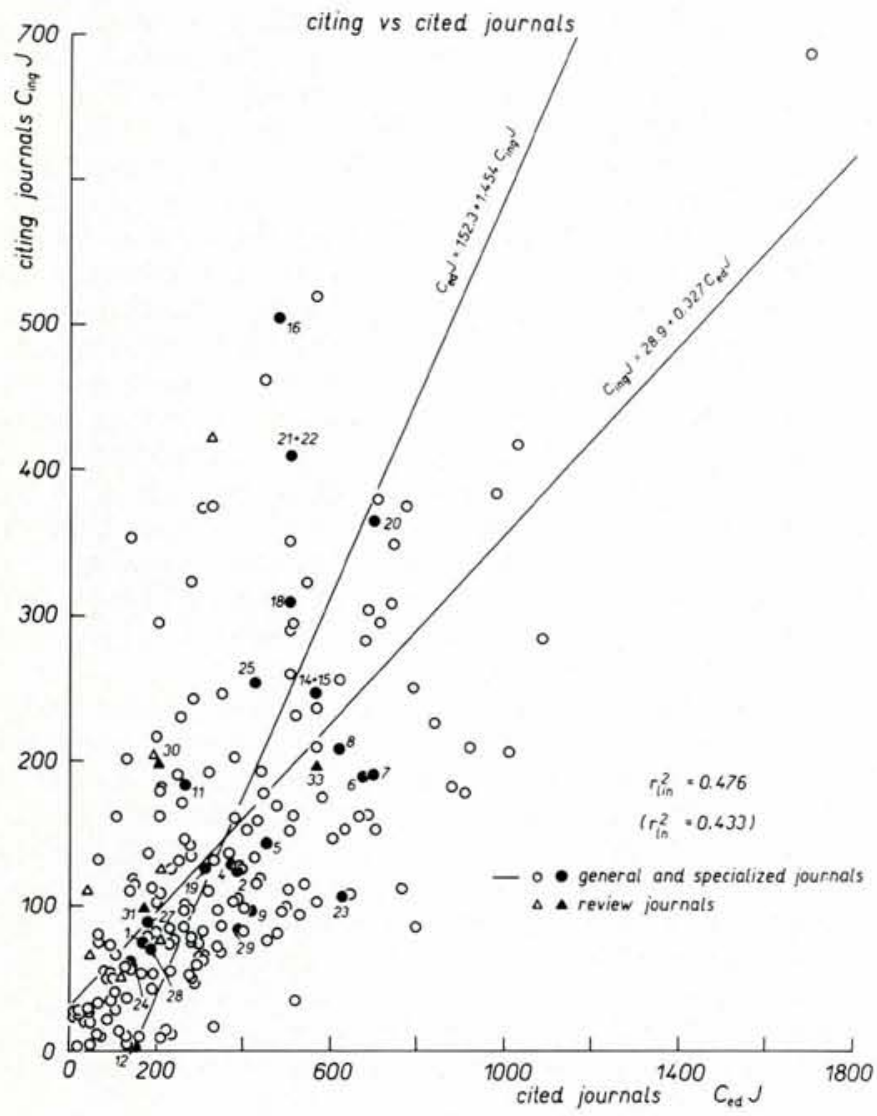

EUROPHYSICS AND WORLD PHYSICS JOURNALS IN COMPARISON

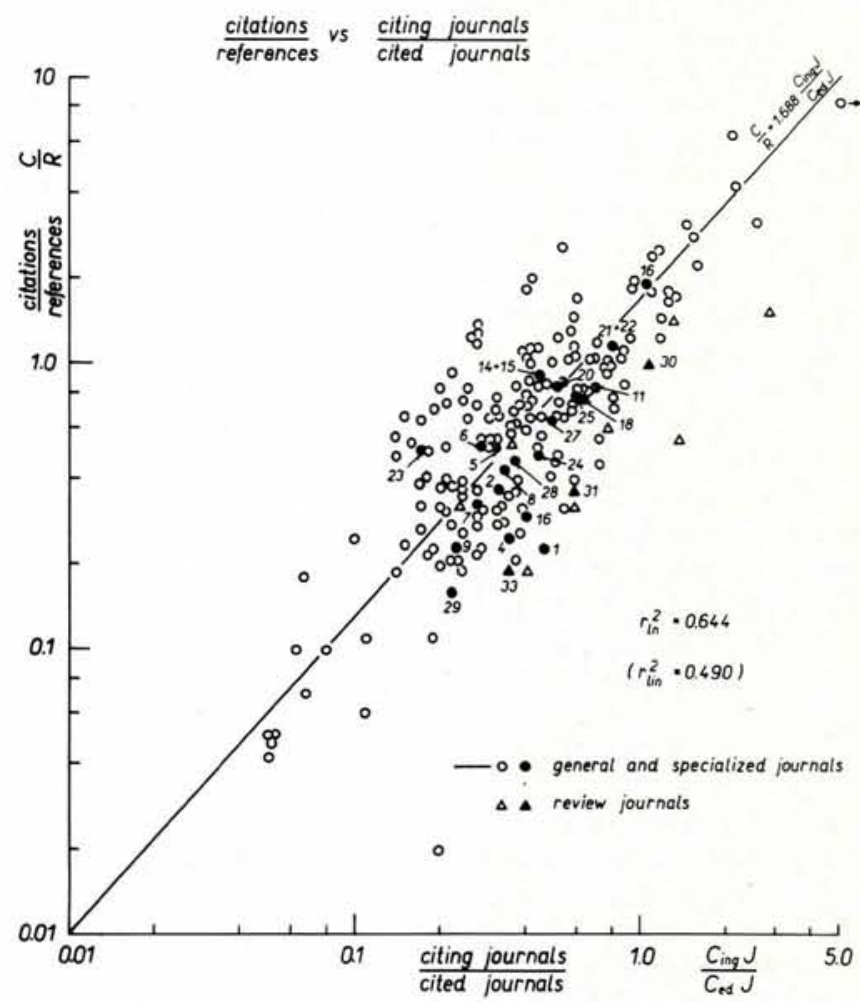

For the key to the Europhysics Journals picked out in the Scatter Diagrams printed above, and for a definition of some of the terms used, see column opposite. 